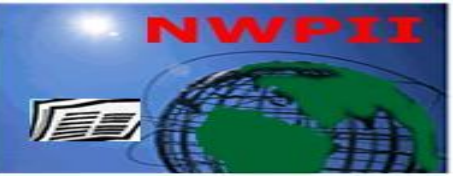

American Journal of Biomedical Sciences

ISSN: 1937-9080

nwpii.com/ajbms

\title{
Comparison of Kinetics of Hemoglobin Electron Transfer in Solution and Immobilized on Electrode Surface
}

\author{
Chen-zhong Li ${ }^{1 *}$, Guodong Liu ${ }^{2 *}$, Shradha Prabhulkar ${ }^{1}$ \\ ${ }^{1}$ Nanobioengineering/Bioelectronics Lab, Department of Biomedical Engineering, Florida International University, \\ Miami, FL, USA \\ ${ }^{2}$ Department of Chemistry and Molecular Biology, North Dakota State University, Fargo, ND, USA \\ *Corresponding authors \\ Dr. Chenzhong Li \\ Nanobioengineering/Bioelectronics Lab. \\ Department of Biomedical Engineering \\ Florida International University \\ 10555 W. Flager St. Miami, Florida 33174 \\ Tel: 3053480120 \\ Email: $\underline{\text { licz@fiu.edu }}$ \\ Dr. Guodong Liu \\ Department of Chemistry and Molecular Biology, \\ North Dakota State University, 158 Dunbar Hall \\ Fargo, ND 58105-5516 \\ Email: guodong.liu@ndsu.edu
}

Received: 14 April 2009; | Revised: 23 May 2009; | Accepted: 25 June 2009

\begin{abstract}
The electron transfer properties of horse heart hemoglobin are compared using a hydrophilic indium tin oxide electrode and a dilaurydimethylammonium bromide (DDAB) polymer modified PG electrodes. A clear, stable and quasi-reversible redox curve of hemoglobin $(\mathrm{Hb})$ was obtained in the absence of electron transfer mediators or promoters. The formal redox potential of $-0.17 \mathrm{vs}$. $\mathrm{Ag} / \mathrm{AgCl}$ of $\mathrm{Hb}$ was determined. The effects of the sixth axial binding ligands including cyanoand azido binding ligands on the redox properties of $\mathrm{Hb}$ were investigated. There are no significant impacts of these ligands on the redox properties of $\mathrm{Hb}$, whereas big effects of the binding ligand on the electrochemical properties of myoglobin were reported. The cyclic voltammetric behavior of hemoglobin was also studied in a DDAB film coated on a pyrolytic graphite electrode. Surface immobilized $\mathrm{Hb}$ in DDAB film gave direct, quasi-reversible, nondiffusion-kinetic-controlled electron transfer on the electrode surface. The formal redox potential for $\mathrm{Hb}$ in the DDAB film negatively shifted about $140 \mathrm{mV}$ as compared to the diffusion-controlled redox reaction of $\mathrm{Hb}$.
\end{abstract}

Keywords: Hemoglobin; interface; fast electron transfer; kinetics; electrode polarity; ligand binding; indium tin oxide. 


\section{Introduction}

The four chains of the hemoglobin molecule are held together by noncovalent attractions. Each chain contains a heme group and a single oxygenbinding group. Heme containing proteins function as oxygen carriers, electron carriers or enzymes in biological systems. Hemoglobin transfers molecular oxygen from the lungs where oxygen concentration is high, to tissue, where the oxygen concentration is low, and carries carbon dioxide back to the lungs. Of particular interest to this investigation is the ability of heme proteins to serve as electron carriers. The alpha and beta chains making up normal hemoglobin differ in number and sequence of amino acids. The heme group, an iron atom bound to the four nitrogen of a porphyrin ring system, is the characteristic structural feature in common to all heme proteins. Oxygen binds to the sixth axial position of the reduced iron in the porphyrin ring. The iron atom serves as the site of oxidation or reduction during electron transfer. Only the reduced heme iron $\left(\mathrm{Fe}^{2+}\right)$ can bind molecular oxygen. The reduced hemoglobin in the absence of oxygen is named deoxyhemoglobin, which has no sixth axial ligand and low spin iron. The met or oxidized hemoglobin had $\mathrm{Fe}^{3+}$ in mixed spin states and water as the sixth ligand [1-2]. Extended X-ray absorption fine structure studies have offered evidence that the displacement of the iron into and out of the porphyrin plane is not as large as originally thought by Fermi et al. [4]. The $\mathrm{Fe}^{2+}$ in deoxyhemoglobin resides on the oxygen approximately $0.7 \AA$ below the plane of the porphyrin ring as its ionic radius is too large to fit into the heme cavity. Upon binding to oxygen, the ionic radius decreases, though the partial excess negative charge resides on the oxygen molecule. The iron moves toward the porphyrin plane in the oxyhemoglobin. The displacement of the histidine covalently attached to the fifth axial position produces small changes in the tertiary structure of the subunit affecting the interaction with other subunits. Although hemoglobin functions physiologically as an oxygen carrier rather than an electron carrier, it is an ideal molecule to use as a model for the study of the electron transfer reactions of heme proteins.

Heterogeneous electron transfer investigations with hemoglobin have been more limited due to the multiple redox centers within the protein. The first direct electron transfer observed with solution hemoglobin was reported at a mercury electrode in 1972 by Scheller et al [5]. They reported evidence of complete reduction of the tetrameric structure at a mercury electrode. The diffusion limited current and half wave potential were independent of $\mathrm{pH}$ over the range of 5.5 to 8.0 , in contrast to myoglobin [6,7]. The polarographic properties of hemoglobin adsorbed at the dropping mercury electrode were reported in which the electron transfer kinetics of hemoglobin was very irreversible [8]. The mechanisms of electron transfer between the solution hemoglobin and mercury electrodes are similar to the mechanisms reported for cytochrome C. However, hemoglobin exhibits a much lower rate of electron transfer at the electrode surface compared to myoglobin and cytochrome $\mathrm{C}$. There possible reasons for this lower rate are its extended three-dimensional structure and multiple redox centers within the protein. Because of slow rates of electron transfer between hemoglobin and solid electrodes, efforts have been made to facilitate the electron transfer of hemoglobin by using mediators, promoters or special electrode materials [9-11]. The direct electron transfer was greatly enhanced for hemoglobin as well as myoglobin in stable lamellar liquid crystal surfactant films [12-13]. Most recently, the electrochemical studies of hemoglobin have also involved primarily heterogeneous electron transfer based on the nano-structural materials [14-17]. However, it still remains a big challenge to obtain direct and rapid electron transfer of hemoglobin at a plain solid electrode.

In this work, we show that adsorbed hemoglobin facilitates direct electron transfer with a bare $\mathrm{In}_{2} \mathrm{O}_{3}$ electrode and simple quasi-reversible redox reactions. The electrochemical behavior of cyanohemoglobin (cyanoHb) and azidohemoglobin (azidoHb) on an $\operatorname{In}_{2} \mathrm{O}_{3}$ electrode was also demonstrated. The preliminary investigation shows that the electrochemical behavior of cyanoHb and azidoHb is quite 
different compared to that of cyanoMb [18]. In this paper, the diffusion controlled electron transfer properties of hemoglobin were compared to non-diffusion kinetic controlled electron transfer using the DDAB (dilauryldimethylamrnonium bromide) film coated on a pyrolytic graphite electrode, on which a well-defined quasi-reversible wave for myoglobin was successful obtained [19-20].

\section{Experimental}

\subsection{Materials}

Horse heart hemoglobin from Sigma was purified and separated by FPLC method on a column of Mono S HR 5/5, or by ion exchange chromatography on a Whatman CM 52 column at $4{ }^{\circ} \mathrm{C}$. The pure sample of hemoglobin was further confirmed by using SDS-PAGE technique that gave a single band having a molar mass of approx 68,000 (Fig. 1). The concentration of ferrihemoglobin was estimated by absorption spectroscopy $\left(\mathrm{E}_{460}=1.62\right.$ $\left.\mathrm{x} 10^{5} \mathrm{M}^{-1} \mathrm{~cm}^{-1}\right)$. The purified hemoglobin was used immediately after purification. Sodium cyanide, sodium azide and DDAB were purchased from Sigma. CyanoHb and azidoHb were obtained upon the addition of a large excess of either sodium cyanide or sodium azide respectively to hemoglobin solutions. All solutions were prepared in distilled and deionized water exhibiting a resistivity of $18 \mathrm{Mohms} / \mathrm{cm}$. All other chemicals used in this work were reagent grade. All measurements were taken under nitrogen at $25^{\circ} \mathrm{C}$.

\subsection{Apparatus and procedures}

A three-electrode system was employed, incorporating $\mathrm{In}_{2} \mathrm{O}_{3}$ or DDAB-Hb modified PG electrodes as the working electrode. Prior to each experiment, the $\operatorname{In}_{2} \mathrm{O}_{3}$ electrode was cleaned by ultrasonication in ca. 5\% aqueous New-vista (the anionic surfactant, AIC Corp.) solution, followed by ultrasonic washing in ethanol and then in MilliQ water for about 24 hours until the required hydrophilicity was obtained (surface tension at least over 60 dyn em. ${ }^{1}$ ). The surface hydrophilicity was measured using a Shimadzu DT-1 surface tensometer by the Wilhelmy method.
Basal plane pyrolytic graphite (PG) disk electrodes were abraded with metallographic Sic sand paper, and then polished to a mirror surface before each experiment with $0.5 \mu \mathrm{m}, 0.3 \mu \mathrm{m}$ and $0.05 \mu \mathrm{m} \mathrm{Al}_{2} \mathrm{O}_{3}$ respectively. The electrode was then ultrasonicated in $\mathrm{EtOH}$ and then in water for about 3 minutes to remove the abraded carbon and residual polishing materials. Enough DDAB was suspended in Milli-Q water to make a $10 \mathrm{mM}$ solution and then was ultrasonicated for 5 hours. $\mathrm{Hb}$-DDAB films were prepared by depositing 10 $\mu \mathrm{l}$ of a dispersion of 1 part $100 \mu \mathrm{M}$ hemoglobin and 1 part $10 \mathrm{mM}$ DDAB onto a PG electrode with a microsyringe. A small bottle was fitted tightly over the electrode overnight so that the water evaporated slowly. Then the films were dried in air for at least 2 hours. The electrochemical measurements were taken by inserting the DDAB-Hb modified PG electrode in a phosphate buffer solution with a platinum foil as an auxiliary electrode and Ag I AgCI (Sat. KCI) as a reference electrode. Voltammetry on electrodes coated with DDAB-Hb films was done in buffers containing no hemoglobin.

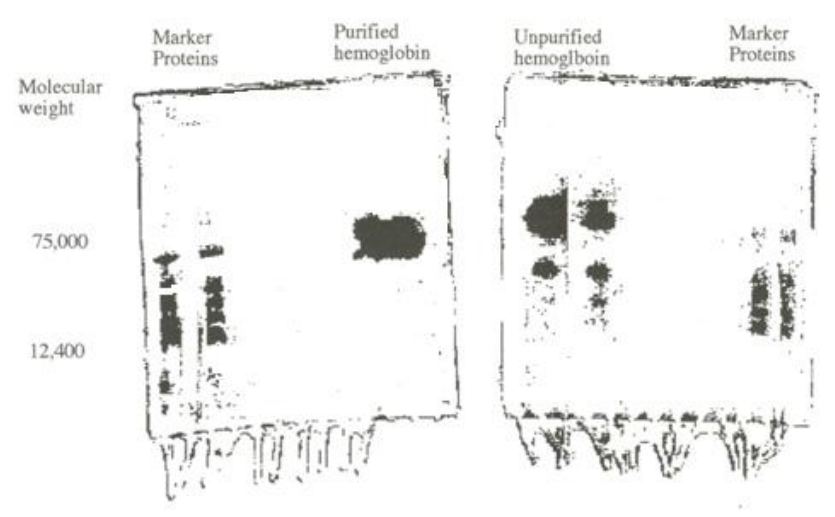

Figure 1. The SDS-polyacrylamide gel electrophoresis patterns of hemoglobin before (left) and after purification (right).

Cyclic voltammograms (CV) were obtained at $25^{\circ} \mathrm{C}$ using a BAS-5O W electrochemical analyzer (Bioanalytical Systems) and a Cypress CS-1090 Computer Controlled Electroanalytical System (Cypress Systems Inc.). UV-vis absorption spectroscopy was done with a Simadzu UV-3100 
spectrophotometer. Prior to experiments, buffer solutions were purged with highly purified nitrogen for at least 30 minutes to remove oxygen and a nitrogen atmosphere was maintained over solutions during experiments. AFM images were obtained with SPA 300 AFM/STM Instrument (Seiko Co.).

\section{Results and discussion}

\subsection{Voltammetry of hemoglobin at a hydrophilic $\mathrm{In}_{2} \mathrm{O}_{3}$ electrode}

Fig. 2 shows the cyclic voltammogram of 80 $\mu \mathrm{m}$ of hemoglobin on a hydrophilic $\mathrm{In}_{2} \mathrm{O}_{3}$ electrode in a phosphate buffer solution containing $0.1 \mathrm{M} \mathrm{NaClO}_{4}$. A very stable and well defined redox wave was observed after several cycles of $\mathrm{CV}$ scans. The formal redox potential $E^{0}$, evaluated from the redox wave was $0.17 \mathrm{~V}$ vs. $\mathrm{Ag} I \mathrm{AgCl}$ (Sat. KCI). The anodic to cathodic peak separation $\Delta \mathrm{Ep}$ is $80 \mathrm{mV}$ at $25^{\circ} \mathrm{C}$. Both anodic (Ipa) and cathodic (Ipc) peak currents increased linearly with the scan rate in the range of $50-200 \mathrm{mV} \mathrm{s}^{-1}$ where the value of the ratio of Ipa to Ipc remained almost constant. Voltammetry on used $\operatorname{In}_{2} \mathrm{O}_{3}$ electrode was also done in the same buffers containing no hemoglobin. The pair of $\mathrm{CV}$ peaks is observed even though the electrode was washed by water several times. These results indicate that redox waves resulted from hemoglobin adsorbed on the electrode surface. The observed reversible

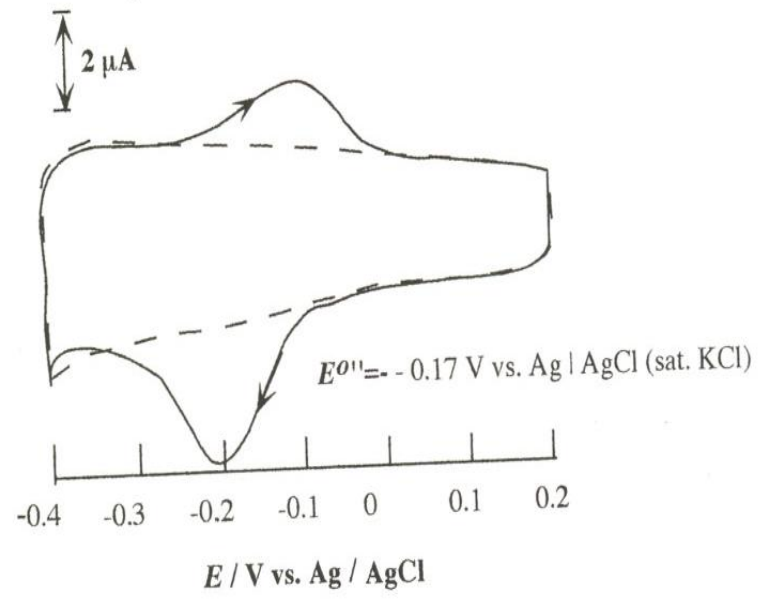

Figure 2. Cyclic voltammograms of $80 \mu \mathrm{M}$ hemoglobin at a hydrophobic $\operatorname{In}_{2} \mathrm{O}_{3}$ electrode in a phosphate buffer solution ( $\mathrm{pH}$ 6.8). Scan rate $=200$ $\mathrm{mV} \mathrm{s}^{-1}$

voltammogram of the adsorbed hemoglobin is stable for many cycles. It is shown that the hemoglobin adsorbed at the electrode is not seriously denatured, i.e., the structural and chemical integrity of hemoglobin is preserved. We refer to the need for hemoglobin to associate at the electrode surface in an adsorption manner that will allow rapid electron transfer with its redox center. In the sense that the protein electrode interaction must be intimate enough to accomplish electron transfer, weak adsorption might be regard as a minimum prerequisite for observation of a sharp and reversible voltammetric response.

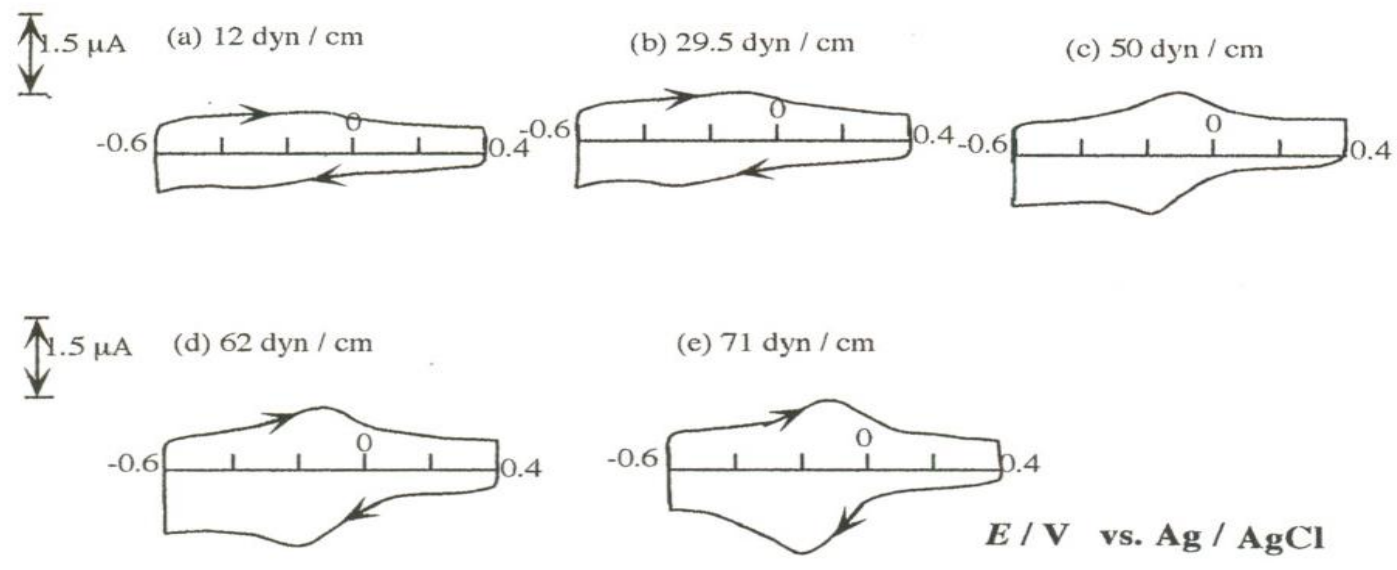

Figure 3. Cyclic Voltammograms of $c a .80 \mu \mathrm{M}$ hemoglobin at various hydrophilic $\mathrm{In}_{2} \mathrm{O}_{3}$ electrodes in a $0.1 \mathrm{M}$ phosphate buffer (pH 6.9) at $25^{\circ} \mathrm{C}$. Scan rate $200 \mathrm{~m} \mathrm{~V} \mathrm{~s}^{-1}$. 


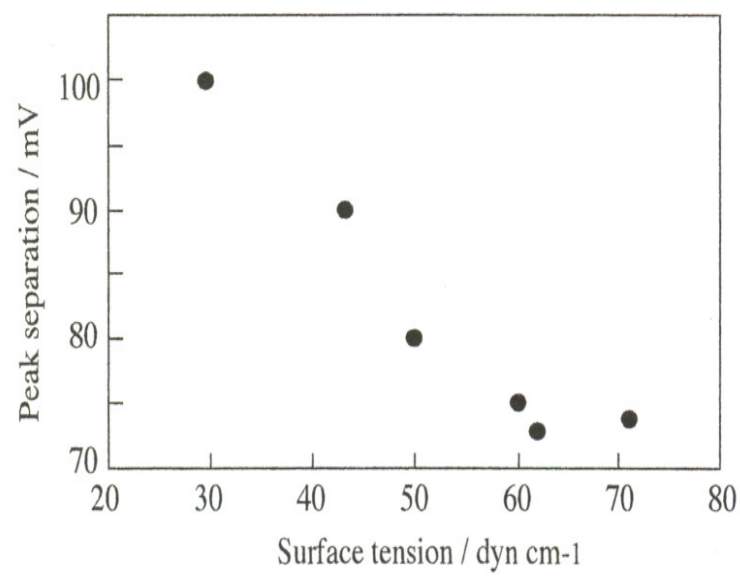

Figure 4. Effects of the hydrophilicity of $\operatorname{In}_{2} \mathrm{O}_{3}$ electrodes surface on peak separation between anodic and cathodic potential.
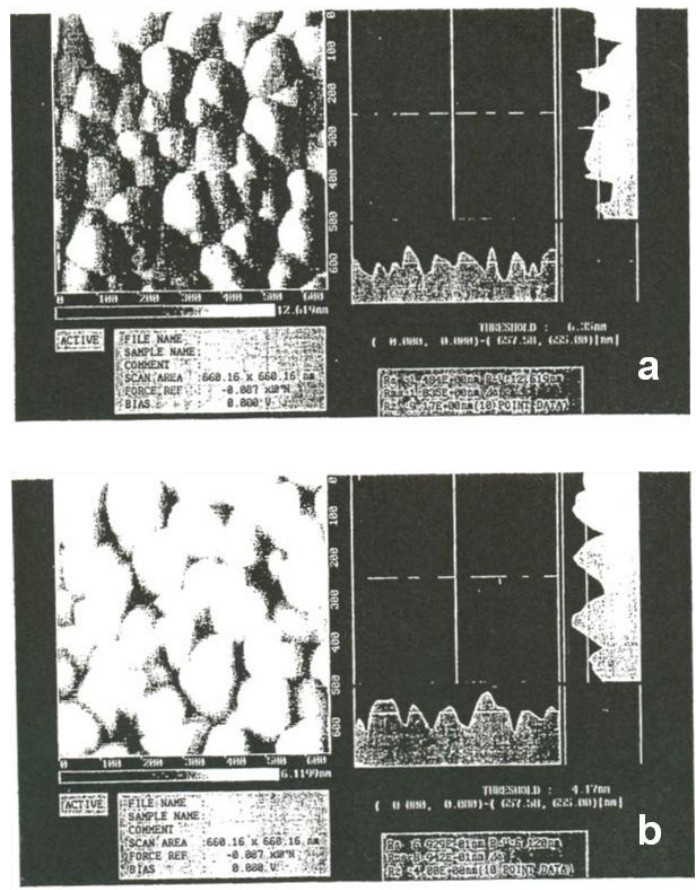

Figure 5. AFM images of (a) the highly hydrophilic surface, (b) the less hydrophilic surface of $1 \mathrm{n}_{2} \mathrm{O}_{3}$ electrodes.

For hemoglobin, the effect of the hydrophilicity of the $\mathrm{In}_{2} \mathrm{O}_{3}$ electrode surface was also examined and a clear dependence of the surface hydrophilicity on the rate of electron transfer on an electrode is shown in Fig. 3 As the electrode surface becomes more hydrophobic (surface tension of $<$ ca. $15 \mathrm{dyn}^{-1}$ ) due to adsorbed organic molecules, no redox wave of hemoglobin is observed. The more the surface becomes hydrophilic, the better redox waves could be obtained for either myoglobin or hemoglobin. The surface tension of the electrode must be close to that of pure water $\left(72 \mathrm{dyn}^{-1}\right.$ at $\left.25^{\circ} \mathrm{C}\right)$ to obtain the best well-defined redox waves. Fig. 4 shows the relationships between the hydrophilicity of the $\operatorname{In}_{2} \mathrm{O}_{3}$ electrode surface and the peak separation. The formal redox potential $E^{O}$ was estimated to be $-0.17 \mathrm{~V}$ vs. $\mathrm{Ag}$ I $\mathrm{AgCl}$ (Sat. $\mathrm{KCl})$. The peak separation will become smaller as the hydrophilicity of the $\operatorname{In}_{2} \mathrm{O}_{3}$ electrode surface becomes higher. The mechanisms of electron transfer between the solution hemoglobin and $\mathrm{In}_{2} \mathrm{O}_{3}$ electrodes have been forwarded by our group. The ferriHb will lose the water molecule as the sixth ligand for the heme when it is reduced to ferroHb, and when the ferroHb is reoxidized, the water molecule could reoccupy the sixth ligand of heme. Fig. 5 shows the typical AFM images of the highly hydrophilic surface of an $\operatorname{In}_{2} \mathrm{O}_{3}$ electrode, together with the less hydrophilic surface of an $\mathrm{In}_{2} \mathrm{O}_{3}$ electrode (observed surface tension $<$ ca. 30 dyn $\mathrm{em}^{-1}$ ). The AFM image for the hydrophilic surface showed that the surface appears more flat than that of the less hydrophilic surface of an $\mathrm{In}_{2} \mathrm{O}_{3}$ electrode. Because more island-like deposits of crystals are well-distributed on the hydrophilic glass plate than in the case for the less hydrophilic surface, the hydrophilic surface of electrode could support more water molecules needed during reoxidization (Fig. 6). Thus, the electrochemical reaction of hemoglobin could occur more easily on the hydrophilic electrode surface. The water molecule attached to the heme as the sixth ligand could promote the electrochemical redox kinetics for the heme group at the electrode surface.

\subsection{Electrochemical behavior of cyanoHb and azidoHb}

FerriHb with the water molecule as the sixth ligand has the high-spin, while ferroHb has high spin as the fifth coordinate [21]. The irreversible cyclic voltammetry of horse skeletal myoglobin came about because the redox process is gated by dissociation and re-association of the bound water (C) 2009 by NWPII. All rights reserved. 
molecule in the $\mathrm{Fe}^{2+}$ form, an example of the electrochemical reaction mechanism [22]. It is known that the rates of electron transfer for cyanoMb are larger compared to those for native myoglobin [18]. On the other hand, cyanide binds strongly to the heme iron active center and forms a low- spin cyanide complex of Fe(III) active heme in native myoglobin, causing complete deactivation of the protein. Both ferri- and ferrocyanoHb have low-spin states. In order to investigate the effect of the spin sate and the sixth ligand of the heme iron on the electron transfer reaction, the electrochemical behavior of cyanoHb and azidoHb was examined.

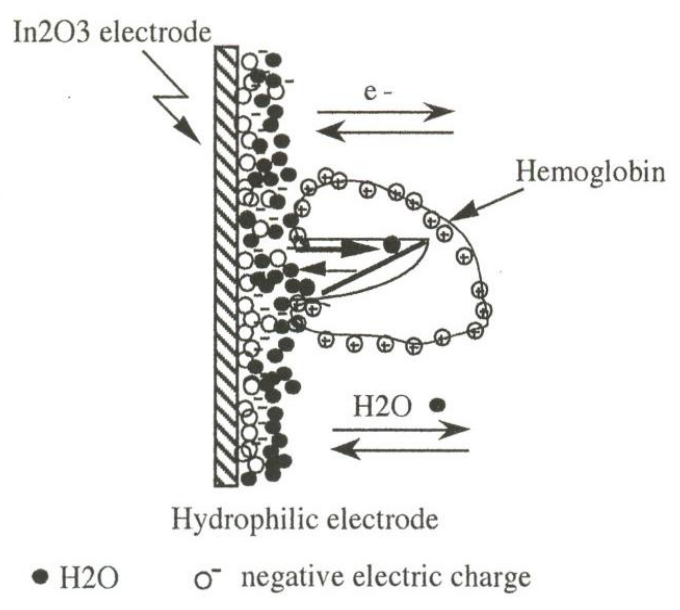

$$
\mathrm{Hb}(\mathrm{III}) \mathrm{H}_{2} \mathrm{O}+\mathrm{e} \rightleftharpoons \mathrm{Hb}(\mathrm{II}) \mathrm{H}_{2} \mathrm{O}
$$$$
\mathrm{Hb}(\mathrm{II}) \mathrm{H}_{2} \mathrm{O} \rightleftharpoons \mathrm{Hb}(\mathrm{II})+\mathrm{H}_{2} \mathrm{O}
$$

Figure 6. Schematic representation of the effect of the hydrophilicity of the $\operatorname{In}_{2} \mathrm{O}_{3}$ electrode surface on the electron transfer of hemoglobin.

Fig. 7 shows the absorbance maximum for ferriHb at $405 \mathrm{~nm}$ changed to ca. $419 \mathrm{~nm}$ and 418 $\mathrm{nm}$ upon the addition of a large excess of sodium cyanide and sodium azide respectively into the ferriHb solution $(\mathrm{pH}=7.5)$. The absorption spectra were almost unchanged for several hours. It is shown that $\mathrm{CN}^{-}$and $\mathrm{N}_{3}{ }^{-}$bind strongly to the heme iron instead of a water molecule as the sixth ligand. Fig. 8 shows a cyclic voltammogram of cyanoHb and hemoglobin at an $\mathrm{In}_{2} \mathrm{O}_{3}$ electrode in phosphate buffer $(\mathrm{pH}=7.5)$ solution. Upon the addition of a large excess of sodium cyanide into a hemoglobin solution, the formal potential shifted Am. J. Biomed. Sci. 2009, 1(4), 303-311; doi: 10.5099/aj090400303 negatively by $40 \mathrm{mV}$ compared to that for hemoglobin. The shape of the cyclic voltammogram and the plot of peak currents vs. scan rate also suggest that the redox process results from the adsorbed cyanoHb on the electrode surface. Fig. 8 also shows no significant difference between the electrochemical response of hemoglobin and azidoHb in the cyclic voltammetric results. Hence, there is no significant difference of electrochemical responses on $\mathrm{In}_{2} \mathrm{O}_{3}$ electrode between the adsorbed cyanoHb or azidoHb and adsorbed hemoglobin. Interestingly, the relationship between the hydrophilicity of the $\mathrm{In}_{2} \mathrm{O}_{3}$ electrode surface and the electrochemical behavior of cyanoHb is different compared to that of hemoglobin. For cyanoHb, no clear dependence of the surface hydrophilicity on the rate of electron transfer at an electrode was obtained. Using an $\mathrm{In}_{2} \mathrm{O}_{3}$ electrode even with a lower hydrophilicity (surface tension about $40 \mathrm{dyn}^{-1}$ ), also shows a well defined cyclic voltammogram for cyanoHb. Thus, the present experimental results compared with hemoglobin suggest that the water molecule coordinated to heme as the sixth ligand might play an important role in the electron transfer process between hemoglobin and a hydrophilic indium oxide electrode.

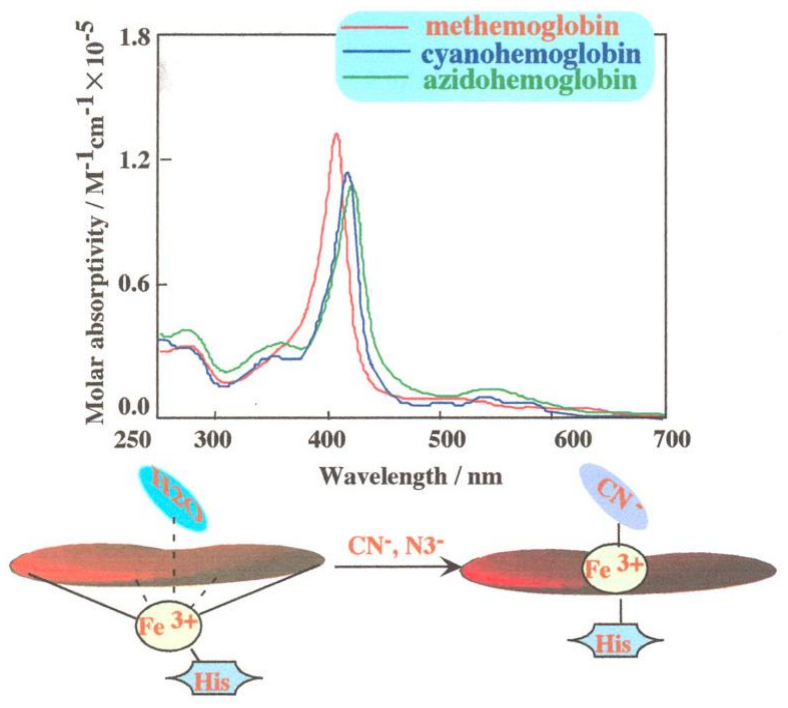

Figure 7. UV-visible spectrums of $\mathrm{Hb}$, cyanoHb $(\mathrm{CN}-$ $: \mathrm{Hb}=400: 1)$ and azidoHb ( Azide:Hb=100:1) in $0.1 \mathrm{M}$ phosphate buffer solutions ( $\mathrm{pH}$ 7.1).

(C) 2009 by NWPII. All rights reserved. 


\subsection{Enhanced electron transfer for hemoglobin in hemoglobin-surfactant film on pyrolytic graphite electrodes}

In order to improve the slow rates of electron transfer between hemoglobin and solid electrodes, functionalized electrodes using mediators, promoters or nanomaterials have been reported by several groups [11-14, 23]. Films cast from didodecyldimethylammonium bromide (DDAB) microemulsions containing myoglobin onto pyrolytic graphite electrodes gave good electron transfer properties [24]. Heterogeneous electrontransfer rates on pyrolytic graphite for the hemoglobin $\mathrm{Fe}^{2+} / \mathrm{Fe}^{3+}$ redox couple in these films was enhanced up to 1000-fold over those in aqueous solution. It was concluded that myoglobin redox reactions in the film were expected for diffusion-kinetic-controlled charge transfer at the electrode-film interface and the charge transport diffusion coefficients were similar to actual diffusion coefficients in solution. In this work, we show that hemoglobin incorporated into DDAB films facilitates direct electron transfer with a PG electrode.

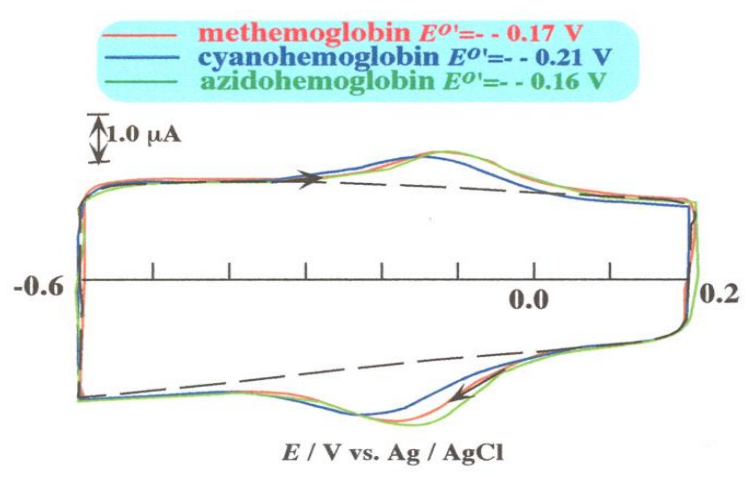

Figure 8. Cyclic Voltammograms of hemoglobin, cyanoHb and zaide $\mathrm{Hb}(c a .80 \mu \mathrm{M})$ at a hydrophilic $\mathrm{In}_{2} \mathrm{O}_{3}$ electrodes in a $0.1 \mathrm{M}$ phosphate buffer ( $\mathrm{pH}$ 6.9) at $25{ }^{\circ} \mathrm{C}$. Scan rate $200 \mathrm{mVs}^{-1}$.

Cyclic voltammetry of hemoglobin dissolved in DDAB microemulsions was observable on bare PG electrodes. However, the curve shapes and large anodic-cathodic peak separations suggested rather slow kinetics and complicated electrode processes. On the other hand, when $\mathrm{Hb}$-DDAB films were deposited on a PG electrode and used in phosphate buffer without dissolved $\mathrm{Hb}, \mathrm{Hb}$ gave well-defined cathodic and anodic peaks with similar peak potentials at low scan rates (Fig. 9). The formal potential estimated as the midpoint between anodic and cathodic peak potentials was $0.28 \mathrm{~V}$ vs. Ag I AgCI (Sat. KCI). The formal potential for hemoglobin in the DDAB film negatively shifted by $170 \mathrm{mV}$ compared to that of diffusion controlled hemoglobin electron transfer in solution. Because $\mathrm{CVs}$ for hemoglobin surfactant film characterization were done after transfering the electrode to buffers containing no hemoglobin, the peaks appearance could be explained due to the $\mathrm{HbFe}$ (III) / $\mathrm{HbFe}(\mathrm{II})$ redox couple although the hemoglobin in these films is partly denatured. The cathodic peak current for the films was directly proportional to scan rate from below $200 \mathrm{mV} \mathrm{s}^{-1}$, as expected for adsorption kinetic-controlled charge transfer at the $\mathrm{Hb}$ DDAB film on PG interface. The storage of the $\mathrm{Hb}$-DDAB film coated PG electrode in buffer for 1 month led to only a $20 \%$ decrease of cathodic peak height at scan rate $50 \mathrm{mV} \mathrm{S}^{-1}$, indicating that the $\mathrm{Hb}-\mathrm{DDAB}$ modified PG electrode was very

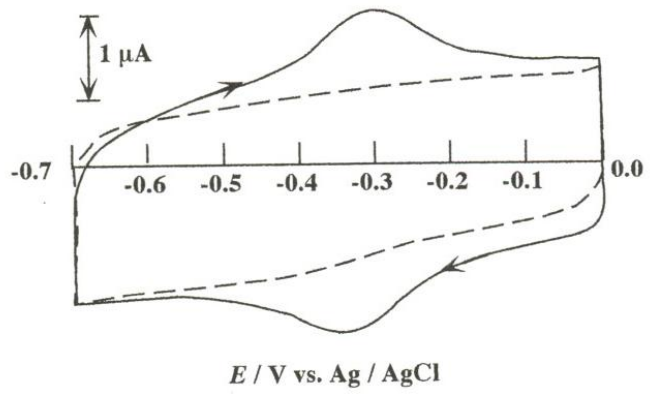

Figure 9. Cyclicvoltammogram of ca. $100 \mu \mathrm{M}$ hemoglobin in DDAB film coated onto a PG electrode surface in a $0.1 \mathrm{M}$ phosphate buffer $(\mathrm{pH}=6.9)$. Scan rate: $200 \mathrm{mVs}^{-}{ }^{1}$, background ( - - ).

stable. The results showed the rate of hemoglobin $\mathrm{Fe}(\mathrm{III}) / \mathrm{Fe}$ (II) electron transfer at $\mathrm{PG}$ was greatly enhanced in DDAB film than at a bare PG electrode. Possible reasons for faster electron transfer in the DDAB films can be proposed; (i) strong adsorption of surfactant onto the electrode that inhibits adsorption of macromolecule impurities from solution [25] which can block electron transfer and (ii) The hydrophilic (C) 2009 by NWPII. All rights reserved. 
environment is known to be very important for rapid electron transfer of proteins [26]. Hemoglobin-DDAB film immobilized on the electrode surface may provide an appropriate microenvironment for protein to maintain its biological and electrochemical activities. It is assumed that the arrangement of hemoglobin incorporated in a DDAB film may retain a favorable orientation for exchanging electrons with the electrode, leading to a relatively high and stable electrochemical activity.

\section{Conclusion}

The electrochemical properties of horse heart hemoglobin have been studied using a very hydrophilic $\mathrm{In}_{2} \mathrm{O}_{3}$ electrode and a PG electrode which is coated with hemoglobin-DDAB surfactant film. A clear, stable and quasireversible redox wave of hemoglobin is obtained at a hydrophilic $\operatorname{In}_{2} \mathrm{O}_{3}$ electrode without a promoter or mediator. The redox properties of cyanoHb and azidoHb also were researched using a hydrophilic $\mathrm{In}_{2} \mathrm{O}_{3}$ electrode. There is no significant difference between cyanoHb, azidoHb and hemoglobin, unlike the case of cyanoMb and myoglobin. Hemoglobin forms stable films with water insoluble, lamellar liquid crystal DDAB by spontaneous insertion from aqueous solutions. The electron transfer rate from hemoglobin to the PG electrode surface could be enhanced in hemoglobin-DDAB film. Hemoglobin in stable films of DDAB gave direct, quasi-reversible, adsorption-kinetic-controlled electron transfer with PG electrodes.

\section{Acknowledgements:}

This current work is partially supported under grant FA9550- 07-1-0344 of Department of Defense/ Air Force Office of Scientific Research, FIU Faculty Research Award, Everglade Foundations and NSF MRI 0821582 grant.

\section{References}

1. Detrich, J. L.; Erb, G. A.; Beres, D. A.; Rickard, L. H., Thermodynamic and electrochemical studies of the electron transfer reactions of hemoglobin, Charge and Field Effects in Biosystems, 1992, 41.

2. Hlastala, M. P.; McKenna, H. P.; Franada, R. L.; Detter, J. C., Influence of carbon monoxide on hemoglobin-oxygen binding, Journal of Applied Physiology, 1976, 41, 893-899.

3. Shulman, R. G., On extended x-ray absorption fine structure studies of hemoglobin, Proceedings of the National Academy of Sciences, 1987;84:973-974.

4. Fermi, G.; Perutz, M. F.; Shaanan, B.; Fourme R., The crystal structure of human deoxyhaemoglobin at $1.74 \AA$ resolution, Journal of Molecular Biology, 1984, 175, 159174.

5. Bestso, S. R.; Cover, R. E., Electrochemical reduction of human methaemoglobin, Journal of the Chemical Society, Chemical Communications, 1972, 172, 621-622.

6. Scheller, F.; Jänchen, M.; Lampe, J.; Prümke, H. J.; Blanck, J.; Palecek, E., Studies on electron transfer between mercury electrode and hemoprotein, Biochimica et biophysica acta, 1975, 412, 157.

7. Gu, H. Y.; Yu, A. M.; Chen, H. Y., Direct electron transfer and characterization of hemoglobin immobilized on a Au colloidcysteamine-modified gold electrode, Journal of Electroanalytical Chemistry, 2001, 516, 119-126.

8. Kuznetsov, B. A.; Shumakovich, G. P.; Mestechkina, N. M., Hydrophilic and hydrophobic domains in the flat protein conformomer as a cause of double step polarographic waves, Journal of electroanalytical chemistry and interfacial electrochemistry, 1988, 248, 387-398.

9. Guo, Z.; Chen, J.; Liu, H.; Cha, C., Direct electrochemistry of hemoglobin and myoglobin at didodecyldimethylammonium bromide-modified powder microelectrode and application for electrochemical detection of nitric oxide, Analytica Chimica Acta, 2007.

10. Ciureanu, M.; Goldstein, S.; Mateescu, MA., Direct electron transfer for hemoglobin in surfactant films cast on carbon electrodes, Journal of the Electrochemical Society, 1998, $145,533$.

C 2009 by NWPII. All rights reserved. 
11. Dai, Z.; Liu, S.; Ju, H.; Chen, H., Direct electron transfer and enzymatic activity of hemoglobin in a hexagonal mesoporous silica matrix, Biosensors and Bioelectronics, 2004, 19, 861-867.

12. Lu, Z.; Huang, Q.; Rusling, JF., Films of hemoglobin and didodecyldimethylammonium bromide with enhanced electron transfer rates, Journal of Electroanalytical Chemistry, 1997, 423, 59-66.

13. Yang, J.; Hu, N.; Rusling, J. F., Enhanced electron transfer for hemoglobin in poly (ester sulfonic acid) films on pyrolytic graphite electrodes, Journal of Electroanalytical Chemistry, 1999, 463, 53-62.

14. Yang, P.; Zhao, Q.; Gu, Z.; Zhuang, Q., The electrochemical behavior of hemoglobin on SWNTs/DDAB film modified glassy carbon electrode, Electroanalysis, 2004, 16.

15. Lu, Q.; Hu, S.; Pang, D.; He, Z., Direct electrochemistry and electrocatalysis with hemoglobin in water-soluble quantum dots film on glassy carbon electrode, Chemical Communications, 2005, 2005, 2584-2585.

16. Salimi, A.; Sharifi, E.; Noorbakhsh, A.; Soltanian, S., Direct voltammetry and electrocatalytic properties of hemoglobin immobilized on a glassy carbon electrode modified with nickel oxide nanoparticles, Electrochemistry Communications, 2006, 8, 1499-1508.

17. Wang, S.; Xie, F.; Liu, G., Direct electrochemistry and electrocatalysis of heme proteins on SWCNTs-CTAB modified electrodes, Talanta, 2009, 77, 1343-1350.

18. King, B. C.; Hawkridge, F. M.; Hoffman, B. M., Electrochemical studies of cyanometmyoglobin and metmyoglobin: implications for long-range electron transfer in proteins, Journal of the American Chemical Society, 1992, 114, 10603-10608.

19. Li, C.-Z.; Taniguchi I.; Mulchandani, A., Redox properties of engineered ruthenium myoglobin, Bioelectrochemistry, 2009, in press.

20. Li. C.-Z.; Nishiyama, K.; Taniguchi, I., Electrochemical and spectroelectrochemical studies on cobalt myoglobin, Electrochim. Acta, 2000, 45, 2883-2888.

21. Quillin, M. L.; Arduini, R. M.; Olson, J. S., Phillips GN: High-resolution crystal structures of distal histidine mutants of sperm whale myoglobin, Journal of molecular biology, 1993, 234, 140-155.

22. Hoard, J. L., Stereochemistry of hemes and other metalloporphyrins, Science, 1971, 174, 1295-1302.

23. Yin, F.; Shin, H. K.; Kwon, Y. S., Direct electrochemistry of hemoglobin immobilized on gold electrode by Langmuir-Blodgett technique, Biosensors and Bioelectronics, 2005, 21, 21-29.

24. Rusling, J. F.; Nassar, A. E. F., Enhanced electron transfer for myoglobin in surfactant films on electrodes, Journal of the American Chemical Society, 1993, 115, 11891-11897.

25. Armstrong, F. A.; Hill, H. A. O.; Walton, N. J., Direct electrochemistry of redox proteins, Accounts of Chemical Research, 1988, 21, 407-413.

26. Yeh, P.; Kuwana, T., Reversible electrode reaction of Cytochrome c, Chem. Lett., 1977, $6,1145-1148$. 